\title{
A concordância em expressões nominais coordenadas com apenas um determinante ${ }^{1}$ \\ Madalena Colaço \& Carolina Gramacho \\ FLUL/CLUL
}

\begin{abstract}
:
This paper provides a corpus-based study of agreement in coordinate nominal expressions with only one determiner in European Portuguese. The data presented in our previous work attested the use of these expressions in written discourse, contradicting what is stated in some grammars. A distinction between two constructions is established: (a) those in which the coordinate nominal expression refers only one entity, which are commonly considered acceptable in grammatical descriptions; (b) those in which nouns are used to refer distinct entities, which are often considered anomalous or even ungrammatical. We focus especially on structures involving a singular determiner and two singular nouns and observe the type of agreement triggered by the nominal expression in each case: singular agreement versus plural agreement. Our proposal is based on the idea that these constructions correspond to structures that are distinct from the beginning of syntactic derivation, differing with respect to the coordinated categories (NP versus DP) and the number of determiners selected for the numeration (only one determiner from the beginning versus two determiners in the beginning and post-syntactic deletion of the second determiner), and provides a simple account of internal and external agreement facts.
\end{abstract}

Keywords: NP coordination, DP coordination, agreement, partial agreement, determiner

Palavras-chave: coordenação de NPs, coordenação de DPs, concordância, concordância parcial, determinante

\section{O problema}

É comum a ideia de que, à semelhança do que se verifica noutras línguas românicas - como o francês e o italiano -, em português europeu (PE) existem fortes restrições sobre os DPs com o formato linear $<$ Determinante-Nome-Conjunção Copulativa-Nome>.

Esta ideia está presente em diversas gramáticas do português, por exemplo, em Cunha \& Cintra (1984), Matos \& Raposo (2013) e Peres (2013). De acordo com estes autores, em PE, as expressões nominais com uma estrutura coordenada com um único determinante ocorrem apenas em contextos específicos, nomeadamente: (i) quando os nomes referem conjuntamente uma mesma entidade, em expressões como "o dono e diretor da escola" ou "o médico e cientista"; (ii) quando os nomes são tomados como um todo, em expressões como "a bondade e generosidade da Ana" ou "o entusiasmo e empenho dos alunos".

\footnotetext{
${ }^{1}$ Este trabalho foi desenvolvido no Centro de Linguística da Universidade de Lisboa (CLUL), unidade de I\&D financiada pela Fundação para a Ciência e a Tecnologia ( UID/LIN/00214/2013). Agradecemos os comentários que nos foram feitos durante o XXXIII Encontro Nacional da Associação Portuguesa de Linguística, bem como os comentários e as sugestões dos revisores da primeira versão deste texto.
} 
As expressões nominais com o formato referido são também comummente aceites quando o determinante e ambos os nomes ocorrem em formas do masculino plural, em expressões como "os livros e manuais recomendados pelo professor".

Para vários falantes do PE, e de acordo com o que está descrito nas gramáticas referidas, existe um nítido contraste, por exemplo, entre (1) e (2), já que apenas em (1) se admite que os nomes possam estar a ser usados para referir conjuntamente uma mesma entidade:

(1) O Pedro conheceu a colega e amiga da Maria.

(2) O Pedro conheceu a mãe e irmã da Maria.

Com efeito, enquanto em (1) os nomes envolvidos referem propriedades, em (2), os nomes obrigam a uma interpretação de pares de indivíduos. Nesta perspetiva, um constituinte nominal como o que ocorre em (1), referindo necessariamente uma única entidade, irá desencadear concordância verbal no singular, como acontece em (3):

(3) A colega e amiga da Maria viajou para o Brasil.

Ainda nesta linha de pensamento, para que os nomes envolvidos na coordenação refiram entidades distintas, cada um deles estará necessariamente associado a um determinante e o constituinte coordenado irá desencadear concordância verbal no plural, como acontece em (4):

(4) A mãe e a irmã da Maria viajaram para o Brasil.

No entanto, em Colaço \& Gramacho (2018), mostrámos, a partir da observação de dados de corpora, um uso bastante mais alargado de constituintes nominais coordenados com apenas um determinante, que parece aproximar o PE de línguas como o espanhol. Os dados apresentados mostraram a coexistência, para alguns falantes do PE, de duas construções:

(i) Uma construção que segue o que está descrito nas gramáticas, na qual os nomes envolvidos na coordenação denotam a mesma entidade. Neste caso, quando o determinante e os nomes ocorrem no singular, o constituinte coordenado desencadeia concordância no singular, como acontece em (5):

(5) A força e impacto do filme deveu-se à convincente interpretação de Montand, à violência da cena do interrogatório, mas principalmente ao facto da história ser verdadeira.

(http:www.linguateca.pt/CETEMPublico, par=ext238444-pol-96b-2 )

(ii) Uma construção que contraria o que está descrito nas gramáticas, na qual os nomes envolvidos na coordenação denotam entidades distintas. Neste caso, quando o determinante e os nomes ocorrem no singular, o constituinte coordenado desencadeia concordância no plural, como se verifica em (6):

(6) O PSP informou ainda que a heroína e cocaína eram pertença da dona da casa onde decorreu a operação e de uma sua filha, de 27 anos.

(idem, par=ext1394741-soc-94a-1)

O objetivo deste estudo é, então, a partir de dados de corpora e da comparação entre o PE e outras línguas, discutir a forma como se realiza a concordância entre o determinante e os nomes numa estrutura de coordenação. Esta discussão implica uma reflexão sobre as estruturas sintáticas envolvidas nestas construções. Tratando-se de um trabalho em desenvolvimento, serão apenas consideradas neste estudo expressões 
nominais que têm como núcleo nomes comuns e especificadores correspondentes a determinantes (artigos) definidos. Será tida em conta, fundamentalmente, a concordância com o determinante, embora, pontualmente, seja também observada a concordância com adjetivos pré ou pós-nominais.

\section{A concordância com o determinante em expressões nominais coordenadas noutras línguas românicas}

Em francês e italiano (e noutras línguas não românicas, como o alemão) ${ }^{2}$, quando o único determinante e os nomes ocorrem em formas do singular, não é possível uma interpretação em que os nomes refiram indivíduos diferentes, o que justifica as agramaticalidades de (7) e (8).

(7) * $\mathrm{Ce}$ soldat et marin étaient d'accord. este soldado e marinheiro estar_Pl de acordo (Heycock \& Zamparelli 2005: 7)

(8) *Un uomo e bambino mangiano. um homem e criança comer_Pl (idem)

Com efeito, nestas línguas, quando ocorre apenas um determinante singular, as expressões nominais referem necessariamente um só indivíduo e não pares de indivíduos. Assim, a coordenação, neste caso, não gera pluralidade: o constituinte nominal desencadeia concordância no singular. Veja-se (9):

(9) La collègue et amie de Marie a survécu à un accident d'avion.

a colega e amiga de Marie VAux_Sg sobreviver_PP a um acidente de avião

Por outro lado, Demonte, Alcalde \& Jiménez (2009) e (2011) mostram, com base em dados de corpora, que, contrariamente ao que é comummente assumido na literatura (por exemplo, por Camacho 1999 e 2003), o espanhol (à semelhança do que acontece noutras línguas não românicas, como o inglês) admite a construção com apenas um determinante no singular com vários tipos de nomes, mesmo quando são referidas entidades distintas. Neste caso, o determinante concorda com o primeiro nome da coordenação, mas o DP desencadeia concordância verbal no plural.

(10) La madre e hija cruzaron toda una serie de miradas.

a mãe e filha trocaram toda uma série de olhares

(Demonte, Alcalde \& Jiménez 2011: 180)

Assim, em espanhol, esta construção coexiste com aquela em que a expressão nominal em que ocorrem os nomes refere uma mesma entidade, caso em que a coordenação não gera pluralidade, como acontece em (11), em que o verbo ocorre no singular.

(11) El académico y novelista pronunció su conferencia. o académico e romancista deu a sua conferência (idem)

\footnotetext{
${ }^{2}$ Esta afirmação baseia-se em descrições destas línguas que têm sido apresentadas na literatura. Não podemos excluir a hipótese de trabalhos baseados em dados de corpora poderem mostrar comportamentos dos falantes destas línguas que se afastem dessas descrições.
} 


\section{A concordância com o determinante em expressões nominais coordenadas em português europeu}

Em Colaço \& Gramacho (2018), foi apresentado um conjunto de dados de corpora escritos de texto jornalístico (extraídos da base de dados online CetemPublico, https://www.linguateca.pt/CETEMPublico/) que nos permitiram atestar a ocorrência, em PE, de construções envolvendo expressões nominais coordenadas com apenas um determinante. Note-se que os dados considerados não são significativos do ponto de vista estatístico nem nos permitem fazer qualquer tipo de generalização quanto à sua frequência no discurso dos falantes. No entanto, neste estudo exploratório, permitem-nos atestar a produção efetiva das construções em estudo por parte de um grupo de falantes, num contexto de escrita correspondente a um registo relativamente formal. ${ }^{3}$

As variáveis consideradas para a extração dos dados foram as seguintes: (i) tipos de nomes; (ii) valor de género do determinante e dos nomes; (iii) valor de número do determinante e dos nomes.

No estudo realizado, foram observados cinco paradigmas com a sequência D-N-Conj_Cop-N, correspondentes a diferentes combinações de valores dos traços de número e de género dos constituintes envolvidos. Na tabela seguinte, apresentamos os paradigmas observados, com a indicação do número total de ocorrências registadas para cada caso:

\begin{tabular}{|c|c|c|}
\hline Paradigma & Descrição do paradigma & No de ocorrências $^{\circ}$ \\
\hline A & D_Fem-N_Fem- $e$-N_Masc & 4324 \\
\hline B & D_Pl-N_Pl- $e$-N_Sg & 708 \\
\hline C & D_Sg-N_Sg- $e$-N_Sg & 17300 \\
\hline D & D_Fem-N_Masc- $e$-N_Fem & 0 \\
\hline E & D_Pl-N_Sg- $e$-N_Sg & 8 \\
\hline F & D_Pl-N_Sg- $e$-N_Pl & 1 \\
\hline
\end{tabular}

Tabela 1. Paradigmas considerados e número de ocorrências no corpus

De maneira a obtermos uma primeira amostra para este estudo exploratório, foram selecionadas aleatoriamente 50 frases ilustrativas de cada um dos paradigmas A, B e C. O Paradigma A - construído com base na pesquisa da sequência D_Fem-N_Fem-e-N_Masc - permite testar a variável género. Quanto à variável número, foi testada a partir de dois paradigmas, correspondentes às sequências D_Pl-N_Pl-e-N_Sg (Paradigma B) e D_Sg-N_Sg-e-N_Sg (Paradigma C). Consideraram-se, ainda, as sequências D_FemN_Masc- $e-$ N_Fem (Paradigma D), D_Pl-N_Sg- $e-N \_S g$ (Paradigma E) e D_Pl-N_Sg-e-N_Pl (Paradigma F), apesar da sua consensual marginalidade para os falantes do PE. O número total de ocorrências registadas para estes três paradigmas foi, efetivamente, muito baixo, pelo que estes dados não foram considerados no nosso estudo.

Para o Paradigma A, em que é controlada a variável género ( $\left.\left\langle\mathrm{D} \_F e m-\mathrm{N} \_F e m-e-\mathrm{N} \_M a s c\right\rangle\right)$, o corpus regista, então, 4324 ocorrências, tendo sido possível atestar a presença de coordenações com os diferentes tipos de nomes, como se pode ver em seguida:

\footnotetext{
${ }^{3} \mathrm{O}$ estudo aqui apresentado assenta, como foi referido, em dados de corpora que atestam a produção de expressões nominais com nomes coordenados e um só determinante, que podem referir entidades distintas. A consideração destes dados assenta numa perspetiva descritiva e explicativa da língua e é neste sentido que deve ser encarada.
} 
(a) Nomes abstratos

(12) A força e impacto do filme deveu-se à convincente interpretação de Montand, à violência da cena do interrogatório, mas principalmente ao facto da história ser verdadeira.

(par=ext238444-pol-96b-2)

(13) «Vêem-se claramente as desconfianças e preconceitos da diplomacia espanhola em relação à maçonaria e ao exército em Portugal», afirma Moran.

(par=ext813843-clt-92b-1)

(b) Nomes concretos não animados

(14) Esta tensão irónica - que se conjuga com a moldura e vidro - parece ter ainda outro objectivo: o de baralhar os dados dos sentidos, de revolver os «clichés» do imaginário, para daí fazer emergir um outro texto, no qual fotografia, palavra, moldura e vidro nos falam do valor limitado da representação.

(par=ext474725-nd-92a-2)

(15) Todos os anos morrem na China cerca de oito milhões de pessoas e, à medida que o nível de vida da população melhora, as sepulturas e jazigos são cada vez maiores e mais sofisticadas.

(par=ext1468712-soc-98a-1)

(c) Nomes concretos animados

(16) Para as crianças e público jovem, em época de férias, o Teatro Infantil de Lisboa apresenta, no Teatro do Calvário, às 16h00, «A Grande Aventura».

(par=ext69847-soc-92a-1)

(17) Uma leitura que se aconselha a todas as mães e pais, mesmo que sejam ingratos, desnaturados, beberrões ou geniosos.

(par=ext1264133-nd-95a-1)

Para o Paradigma B, em que é controlada a variável número ( $\left.\left\langle\mathrm{D} \_\mathrm{Pl}-\mathrm{N} \_\mathrm{Pl}-e-\mathrm{N} \_\mathrm{Sg}\right\rangle\right)$, o corpus apresenta 708 ocorrências, tendo sido atestadas coordenações com todos os tipos de nomes em questão, inclusive casos de nomes concretos e animados, associados ao traço [+humano], representando forçosamente entidades distintas.

(a) Nomes abstratos

(18) Os brancos são, quase sempre, servidos muito frios, o que lhes prejudica os aromas e sabor. (par=ext77303-soc-92b-2)

(19) A mostra traça as referências e percurso do manto, da Índia ao arquipélago do Sol Nascente, passando pela etapa fundamental da China e a pelo desenvolvimento de uma indústria e iconografia especificamente japonesas, a partir do século XVIII principalmente.

(par=ext31313-clt-93b-4) 
(b) Nomes concretos não animados

(20) As pessoas em contacto com doentes constipados devem lavar as mãos com frequência e evitar o contacto destas com os olhos e nariz, pois esta é uma forma habitual de auto-inoculação.

(par=ext51045-clt-soc-94a-1)

(21) Os jardins e capela do Palácio do Marquês de Pombal, em Oeiras, são o alvo do $4^{\circ}$ passeio turístico de Santo Amaro de Oeiras que começa às $10 \mathrm{~h} 00$ junto ao posto de turismo.

(par=ext29800-soc-93b-2)

(c) Nomes concretos animados

(22) Foi com esse espírito que os jogadores e treinador dos San Antonio Spurs celebraram no sábado a vitória sobre os Seattle SuperSonics, líderes da Divisão Pacífico e quase certos campeões da Conferência Oriental, por 84-81.

(par=ext44305-des-96a-2)

(23) Todos os passageiros e tripulação sairam ilesos do aparelho, sendo transportados para a aerogare e daí para uma unidade hoteleira onde aguardaram a vinda de outro avião para a viagem de regresso à Suécia, após um período de férias no Funchal, forçadamente prolongado com um óptimo dia de praia no Porto Santo.

(par=ext183053-soc-94b-2)

No Paradigma C, em que também é controlada a variável número ( $\left\langle\mathrm{D} \_S g-\mathrm{N} \_S g-e-\mathrm{N} \_S g\right\rangle$ ), foram encontradas 17300 ocorrências da sequência em causa, registando-se, tal como nos outros paradigmas, coordenações com todos os tipos de nomes em questão, inclusive casos de nomes concretos e animados, associados ao traço [+humano] representando forçosamente entidades distintas, como se pode ver pela concordância sujeito-verbo (veja-se (29)).

(a) Nomes abstratos

(24) A linguagem e estilo de Ribeiro são inconfundíveis, mas é interessante como ele explora, quando trabalha com os bailarinos do Ballet Gulbenkian, um virtuosismo mais expansivo e amplo.

(par=ext819212-soc-96b-1)

(25) Os britânicos também estão apreensivos quanto à maneira como a corporação policial actua e a percentagem dos que consideram que a polícia deveria recorrer à força para manter a lei e ordem passou de três quartos do total dos entrevistados, em 1980, para dois terços hoje em dia.

(par=ext1083890-nd-93b-3)

(b) Nomes concretos não animados

(26) Os cientistas experimentaram fabricar estes filmes utilizando quase todas as matérias primas imagináveis - segundo alguns relatos, entre os materiais experimentados conta-se, por exemplo, o vodka e saké.

(par=ext1120927-nd-91a-1) 
(27) O PSP informou ainda que a heroína e cocaína eram pertença da dona da casa onde decorreu a operação e de uma sua filha, de 27 anos.

(par=ext1394741-soc-94a-1)

(c) Nomes concretos animados

(28) O miúdo, dormindo, é posto no banco de trás, entre as duas mulheres, a empregada e patroa. (par=ext508426-clt-98a-1)

(29) O actor e actriz é difícil de dizer, mas talvez fossem António Vilar (Igrejas Caeiro pela certa) e Leonor Maia. (par=ext872004-clt-95a-1)

Os dados relativos ao Paradigma C mostraram que, quando os DPs coordenados com um só determinante ocorrem na posição de sujeito, a concordância verbal por vezes é feita no singular e outras vezes no plural. Vejam-se os dados apresentados, respetivamente, em (30)-(31) e (32)-(33):

(30) O licenciamento e arbitragem de todo o projecto está nas mãos do Ministério do Ambiente. (par=ext1271799-soc-95a-2)

(31) José Alho afirma que a despoluição e utilização do aquífero é importante não só para a região como para o país, pois é uma «enorme reserva estratégica de um importante recurso como é a água». (par=ext5627-soc-97a-1)

(32) Segundo a Interfax e a Itar-TASS (agência noticiosa oficial), a artilharia e aviação russas estavam ontem activas em Vedeno, Stari Achkoi e bombardeavam ainda alvos perto de Grozni, a capital da Tchetchénia.

(par=ext427818-nd-96a-1)

(33) O título e subtítulo por vós escolhidos não fazem parte dos objectivos ou das conclusões do trabalho científico por mim referido.

(par=ext915473-opi-98a-3)

Estes dados mostraram, então, que, para alguns falantes do PE, está disponível a construção de expressões nominais coordenadas com apenas um determinante, podendo os nomes envolvidos pertencer a diferentes classes. Mostraram também que, para esses falantes, para além de construções em que os nomes que ocorrem na expressão nominal são considerados conjuntamente, como em (34), são também possíveis construções em que a referência dos nomes é independente, como em (35). Esta diferença é evidenciada pela forma como se desencadeia a concordância verbal, uma vez que apenas no segundo caso é desencadeada concordância no plural.

(34) José Alho afirma que a despoluição e utilização do aquífero é importante não só para a região como para o país, pois é uma «enorme reserva estratégica de um importante recurso como é a água». (par=ext5627-soc-97a-1) 
(35) Segundo a Interfax e a Itar-TASS (agência noticiosa oficial), a artilharia e aviação russas estavam ontem activas em Vedeno, Stari Achkoi e bombardeavam ainda alvos perto de Grozni, a capital da Tchetchénia.

(par=ext427818-nd-96a-1)

Estes dados parecem, então, aproximar o PE de línguas como o espanhol, mostrando que, para alguns falantes, contrariando o que é descrito frequentemente nas gramáticas, a presença de apenas um determinante é compatível com a ocorrência da conjunção copulativa com um valor de reunião e não de interseção.

\section{Análises propostas para o espanhol}

Camacho (1999) e (2003) sustenta que, em espanhol, quando, nas expressões nominais, ocorre apenas um determinante, apenas são aceitáveis as construções em que o constituinte coordenado refere uma única entidade, ou seja, quando os nomes referem propriedades que se intersetam, tendo um valor predicativo. Nestes casos, o determinante concorda com o primeiro nome da coordenação e o DP desencadeia concordância no singular, como em (36).

(36) El presidente y secretario general del partido ofreció una rueda de prensa. o presidente e secretário geral do partido ofereceu uma conferência de imprensa (Camacho 1999: 21)

Na linha de Longobardi (1994), o autor adota, para estas construções, uma estrutura de coordenação de DPs plenos (hipótese DP\&DP). De acordo com esta hipótese, a estrutura inicial de uma expressão como "el presidente y secretario general del partido" inclui a presença de um determinante no interior de cada DP. Ao longo da derivação, a relação estrutural de c-comando assimétrico do primeiro termo coordenado sobre o segundo legitima o apagamento do material idêntico (deletion under identity) no segundo DP, como está representado, muito simplificadamente, em (37). Desta forma se explica a concordância obrigatória do determinante com o primeiro nome.

(37) [[DP D N] [and [DP ØD N]]]

Nesta proposta, a obrigatoriedade que o autor postula de os nomes envolvidos na coordenação referirem conjuntamente a mesma entidade é explicada por um mecanismo de coindexação do determinante realizado com o determinante elidido. Assim se explica a impossibilidade de ocorrência de nomes referenciais nesta construção, uma vez que essa coindexação dos determinantes implica que os próprios nomes refiram a mesma entidade. Camacho (2003) relaciona esta impossibilidade com o facto de não ser permitida a coordenação de dois DPs com a mesma referência, como em (38):

(38) *La mujer y la mujer vinieron.

a mulher e a mulher vieram

Também Heycock \& Zamparelli (2005) afirmam que o espanhol se comporta como o italiano, o francês e o alemão, não permitindo a ocorrência de um determinante singular com escopo sobre dois nomes no singular numa leitura em que os nomes têm referentes distintos. Os autores apresentam o seguinte exemplo, que classificam como agramatical pelo facto de obrigar a uma interpretação de referência disjunta: 
(39) *El soldado y pescador estaban luchando. o soldado e pescador estavam lutando (op.cit.:7)

Numa perspetiva diferente, Demonte, Alcalde \& Jiménez $(2009,2011)$ atestam, a partir de corpora (nomeadamente, do Corpus de Referencia del Español Actual), a produção de expressões nominais coordenadas com um determinante no singular e dois nomes também no singular, e mostram que estes podem pertencer a diferentes classes, mesmo quando são referidas entidades distintas. Observem-se os seguintes dados apresentados pelos autores, em que os nomes envolvidos na coordenação remetem necessariamente para referentes distintos:

(40) Su marido e hijo vivían en Río. seu marido e filho viviam em Rio (Demonte, Alcalde \& Jiménez 2009:1)

(41) La madre e hija cruzaron toda una serie de miradas. a mãe e filha trocaram toda uma série de olhares (Demonte, Alcalde \& Jiménez 2011:180)

Os dados apresentados mostram, então, que frases como (40) e (41) existem a par de outras em que o verbo ocorre no singular, estando estas últimas restringidas a uma interpretação em que a expressão nominal coordenada refere uma única entidade.

(42) El académico y novelista pronunció su conferencia. o académico e romancista proferiu sua conferência (idem)

Assumindo-se que, em qualquer dos casos, a coordenação se verifica ao nível do NP (hipótese DET [N/NP\&N/NP]), a diferença entre frases como (40)-(41) e frases como (42) é explicada a partir da forma como se realiza a concordância no interior das expressões nominais, uma vez que, quando os nomes referem entidades distintas, a ocorrência do determinante no singular é vista como o resultado de um fenómeno de concordância parcial com o termo coordenado mais próximo. Encarando a concordância numa perspetiva de feature sharing (cf. Frampton \& Gutmann 2000, 2006), os autores assumem que os nomes entram na derivação sintática associados a um conjunto de traços- $\phi$. No entanto, afirmam que a noção comummente aceite de conjunto de traços- $\phi$ é insuficiente para explicar a concordância com o termo mais próximo, uma vez que o DP, apesar de ser morfologicamente singular, é interpretado como plural, desencadeando concordância plural com o verbo quando ocorre na posição de sujeito. Assim, propõem um enriquecimento da teoria de traços- $\phi$, considerando a existência de dois tipos de feixes de traços associados aos nomes, a que chamam $c$ [concord] $\phi$-features (traços formais) e $i$ [index] $\phi$-features (traços referenciais). ${ }^{4} \mathrm{O}$ feixe de traços- $c$ inclui traços de número, de género e de Caso. Por sua vez, o feixe de traços- $i$ inclui traços de número,

\footnotetext{
${ }^{4} \mathrm{~A}$ ideia de que a concordância envolve diferentes conjuntos de traços está também presente em trabalhos de vários outros autores no âmbito de diferentes quadros teóricos, como King e Dalrymple (2004), Villavicencio et al. (2005), D'Alessandro (2004a) e (2004b), Costa e Pereira (2005), Heycock e Zamparelli (2005), etc.
} 
de género e de pessoa. Considera-se que o traço de pessoa é uma propriedade semântica dos nomes. Esta assunção tem particular relevo em línguas como o espanhol, em que os nomes animados podem estar associados a diferentes valores de pessoa, como acontece em (43).

(43) Los españoles estamos/estáis/están en el rincón.

os espanhóis estar_1P1/2P1/3Pl em o canto

(Demonte, Alcalde \& Jiménez 2011:183)

Por outro lado, os nomes estão associados a traços de género e de número, e têm um traço de Caso abstrato. Relativamente ao determinante, uma vez que $\mathrm{D}$ é um núcleo funcional, os seus traços não estão, à partida, valorados, sendo valorados por agree durante a derivação sintática. Assim, os elementos que participam, por exemplo, na coordenação ilustrada em (41) correspondem à seguinte descrição:

(44) madre

$i[\mathrm{G}(\mathrm{f}) \mathrm{N}(\mathrm{sg}) \mathrm{P}(3)]$

$c[\mathrm{G}(\mathrm{f}) \mathrm{N}(\mathrm{sg}) \mathrm{C}(\mathrm{)})]$

hija $\quad i[\mathrm{G}(\mathrm{f}) \mathrm{N}(\mathrm{sg}) \mathrm{P}(3)]$

$c[\mathrm{G}(\mathrm{f}) \mathrm{N}(\mathrm{sg}) \mathrm{C}(\mathrm{)})]$

$\mathrm{D} \quad i[\mathrm{G}() \mathrm{N}() \mathrm{P}()]$

$c[\mathrm{G}() \mathrm{N}() \mathrm{C}()]$

De acordo com esta proposta, a categoria ConjP não tem traços-c, uma vez que o núcleo Conj não está morfologicamente associado a valores de singular/plural ou masculino/feminino. No entanto, Conj tem traçosi, dado que a coordenação tem como efeito uma combinação dos traços-i dos termos coordenados, através de um mecanismo de resolução, o que decorre do facto de a conjunção copulativa conduzir à formação de um conjunto (por exemplo, viabilizando interpretações grupais). Deste facto resulta que, sendo os nomes singulares, a categoria resultante da coordenação fique associada a um valor plural:

(45)

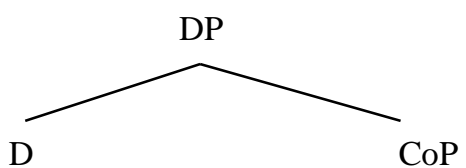

i $[\mathrm{G}() \mathrm{N}($ ) $\mathrm{P}(\mathrm{)})] \longrightarrow \mathrm{i}[\mathrm{G}(\mathrm{f}) \mathrm{N}(\mathrm{pl}) \mathrm{P}(3)]$

c [G( ) N( ) C( )]

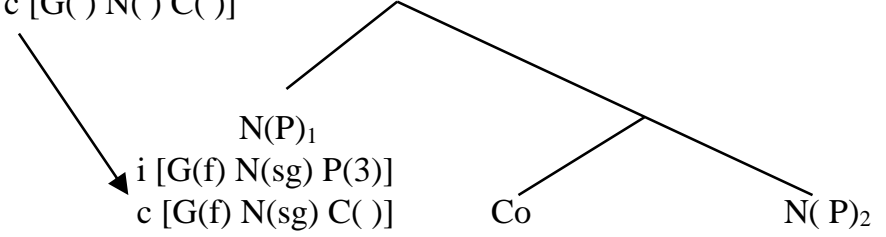

i $[\mathrm{G}[\mathrm{f}] \mathrm{N}[\mathrm{sg}] \mathrm{P}(3)]$

c [G[f] N[sg] C( )]

(Demonte, Alcalde \& Jiménez 2011:184, adaptado)

Uma vez que $\mathrm{D}$ tem traços não valorados, procurará um alvo que permita essa valoração através de agree. $\mathrm{O}$ alvo mais próximo para a valoração dos seus traços-i é ConjP. Assim, os traços-i de D recebem os valores dos traços-i de ConjP. Mas, para a valoração dos traços-c, o alvo mais próximo de $\mathrm{D}$ é o primeiro $\mathrm{N}(\mathrm{P})$. Assim, D recebe os valores dos traços-C do primeiro $\mathrm{N}(\mathrm{P})$. $\mathrm{O}$ facto de este não ter o traço de Caso 
valorado não constitui um problema, uma vez que, na teoria de agree como feature sharing adotada pelos autores, pode haver matching dos traços independentemente de estes estarem ou não valorados. Como resultado destas operações, D é morfologicamente singular, mas, em termos de indexação, é plural. Estes traços, com estes valores, percolam até DP, ficando acessíveis a operações sintáticas.

(46)

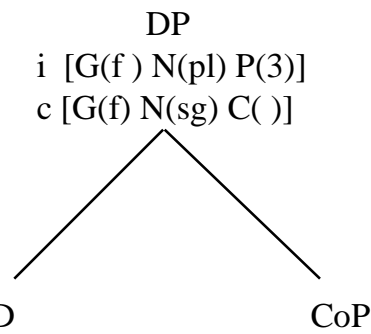

i $[\mathrm{G}(\mathrm{f}) \mathrm{N}(\mathrm{pl}) \mathrm{P}(3)]$

c $[\mathrm{G}(\mathrm{f}) \mathrm{N}(\mathrm{sg}) \mathrm{C}(\mathrm{)})$

Assim, de acordo com esta análise, a coexistência da concordância parcial com uma interpretação plural da coordenação é explicada pelo facto de D valorar os seus traços-i e os seus traços-c com categorias distintas. Em relação à concordância sujeito-verbo, os autores assumem que o núcleo $\mathrm{T}$ está associado a um feixe de traços-c não valorados que inclui traços de género, número e pessoa. Estes traços vão ser valorados por agree com os traços-i do DP, pelo que T passa a ter o valor plural, o que explica que o verbo ocorra no plural. ${ }^{5}$

(47)

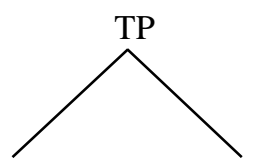

$\mathrm{T}$

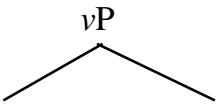

DP

i $[\mathrm{G}(\mathrm{f}) \mathrm{N}(\mathrm{pl}) \mathrm{P}(3)]$

c $[\mathrm{G}(\mathrm{f}) \mathrm{N}(\mathrm{sg}) \mathrm{C}(\mathrm{)})$

(op. cit.:186)

Os autores assumem que a sua proposta apresenta o problema de não permitir explicar de forma satisfatória o modo como o DP vai valorar o traço de Caso a partir de agree com T depois de T valorar os seus traços-c com o DP. De qualquer forma, assumem que a atribuição de Caso resulta de uma operação independente de agree.

\footnotetext{
${ }^{5}$ Como foi referido atrás, esta análise aplica-se apenas às construções em que os nomes são usados para referir entidades distintas.
} 


\section{Proposta de análise para o português europeu}

Os dados que apresentámos na secção 3 mostraram a possibilidade de construirmos, em PE, estruturas de coordenação de expressões nominais com apenas um determinante com diferentes tipos de nomes. Atestaram também a possibilidade, contrariando a ideia que frequentemente se apresenta em algumas gramáticas, de os nomes envolvidos nestas construções referirem entidades distintas, paralelamente à possibilidade de referirem uma mesma entidade. Com o objetivo de contribuir para a análise destas construções, pretendemos, nesta secção, responder às seguintes questões:

(i) Qual a diferença estrutural entre as construções em que as expressões nominais que referem entidades distintas e aquelas em que referem uma mesma entidade?

(ii) Em qualquer dos casos, como se explica a concordância do determinante com o primeiro termo coordenado?

A proposta que apresentamos parte da assunção de que as construções em que as expressões nominais referem a mesma entidade e aquelas em que as expressões nominais referem entidades distintas são estruturalmente diferentes, uma vez que envolvem coordenação de categorias diferentes. A nossa ideia central é, pois, a que enunciamos em (48):

(48) A coordenação envolve NPs quando os nomes são usados para referir a mesma entidade, sendo o valor referencial da expressão nominal construído apenas no momento em que se verifica a aplicação do determinante. A coordenação envolve dois DPs quando os nomes referem entidades distintas, dado que, neste caso, os termos coordenados têm valores referenciais construídos de forma independente.

\subsection{Expressões coordenadas em que os nomes referem conjuntamente uma única entidade: coordenação de NPs}

A observação dos dados permitiu-nos constatar que, nas construções em que os nomes referem uma única entidade e o determinante e os nomes estão no singular, o determinante concorda com o primeiro nome que entra na coordenação. Por outro lado, quando o DP ocorre numa posição desencadeadora de concordância, desencadeia concordância no singular. Sugerimos, então, que, neste caso, é inserido na estrutura sintática apenas um determinante.

Esta ideia é confirmada pelos dados: não existem, na amostragem considerada neste estudo, dados em que os nomes envolvidos na coordenação refiram entidades concretas (animadas ou não animadas). $\mathrm{O}$ único tipo de nomes animados coordenados encontrados foram nomes relacionais que designam relações compatíveis, ou seja, relações em que pode participar uma mesma entidade, como acontece em (49), com os nomes "amigo e colega", e em (50), com os nomes "patrão e amigo":

(49) O meu amigo e colega Juan Mozzicaffredo acaba de publicar, com os seus colaboradores, um documentado estudo que desfaz em grande parte o mito optimista que tem reinado a esse respeito.

(par=ext1359212-nd-91b-2)

(50) Emilio Estevez é Billy the Kid e este filme, de que se faria depois uma continuação, conta-nos a história da sua luta para vingar o seu patrão e amigo, Tunstall, assassinado durante a guerra do condado de Lincoln.

(par=ext859212-nd-92a-5) 
Assumimos, então, que estes casos correspondem a estruturas de coordenação de NPs, ou seja, de categorias abaixo do DP, tal como Demonte, Alcalde \& Jiménez (2009) e (2011) assumem para o espanhol e, por exemplo, Heycock \& Zamparelli (2004) assumem para o inglês, para frases, respetivamente, como as seguintes:

(51) El académico y novelista pronunció su conferencia.

(Demonte, Alcalde \& Jiménez 2011: 180)

(52) My friend and colleague is writting a paper. (Heycock \& Zamparelli 2004: 3)

Nesta perspetiva, estas construções envolvem um único determinante desde a numeração, o que conduz a que o DP refira uma única entidade e explica a interpretação que lhes está associada.

Sendo assim, neste caso, o maior desafio que se coloca diz respeito à forma como se realiza a concordância. Na verdade, como já constatámos, os nomes coordenados podem apresentar valores diferentes dos traços de concordância, sendo que o determinante partilha os valores do primeiro nome, como está ilustrado em (53) e (54):

(53) a. O lançamento e benção da primeira pedra foi rodeado de pompa e circunstância barrocas, a que não faltaram os charameleiros da cidade.

(par=ext1083611-soc-95b-1)

b. Det_Masc-N_Masc-e-N_Fem

(54) a. A conservação e restauro foi abordada de uma forma mais metódica, «fazendo uma limpeza sistemática dos depósitos e das próprias obras, acondicionando-as em caixas de cartão desacidificado, sem agrafos que enferrujem ou colas que atraiam insectos - ou seja, cosidas.

(par=ext865713-clt-98a-2)

b. Det_Fem-N_Fem-e-N_Masc

Assumimos, seguindo o já proposto em Colaço (2012) e (2016), que a concordância parcial do determinante resulta da relação de c-comando assimétrico local que o determinante estabelece com o primeiro termo coordenado ${ }^{6}$, tal como se pode observar na seguinte representação simplificada ${ }^{7}$ :

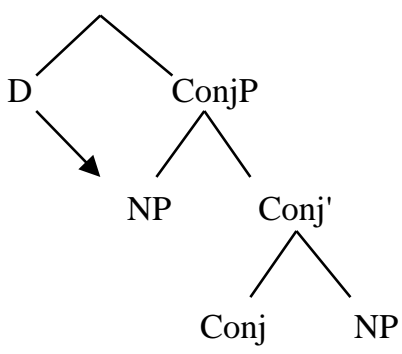

\footnotetext{
${ }^{6}$ Em Colaço $(2012,2016)$, o requisito de assimetria é proposto para explicar a inexistência de concordância entre o determinante e ConjP, que daria origem a concordância plena. Por sua vez, o requisito de localidade é proposto para explicar a inexistência de concordância entre o determinante e o segundo termo coordenado.

${ }^{7}$ Tratando-se de uma representação simplificada, não estão representadas as categorias funcionais que codificam os traços de número (NumP) e género (GenP).
} 
Os valores do determinante percolam até à sua projeção cimeira, razão pela qual o DP assume esses valores, o que explica o facto de o verbo ocorrer no singular quando o primeiro termo é singular.

(56) O lançamento e benção da primeira pedra foi rodeado (...)

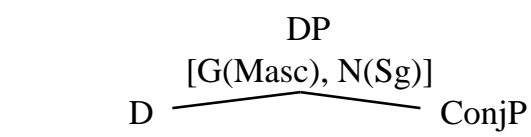

[G(Masc), N(Sg)]

(57) A conservação e restauro foi abordada (...)

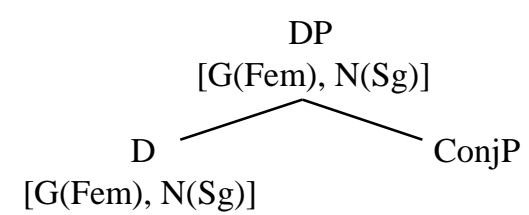

É de notar que, na amostragem considerada, não foi controlada a concordância em género com elementos pós-nominais. No entanto, o que observamos nos dados acima é consistente com a proposta apresentada, uma vez que parece apontar no sentido de esses elementos terem um valor de género idêntico ao do primeiro termo coordenado (e, consequentemente, idêntico ao do determinante).

\subsection{Expressões coordenadas em que os nomes referem entidades distintas: coordenação de DPs}

Os dados que observámos no âmbito deste estudo mostraram que, nas construções em que os nomes referem entidades distintas, quando o determinante e os nomes estão no singular, o determinante concorda com o primeiro nome envolvido na coordenação. Por outro lado, quando o DP coordenado ocorre numa posição desencadeadora de concordância, desencadeia concordância no plural. Assumimos que, neste caso, são inseridos na estrutura sintática dois determinantes, pelo que os termos coordenados são da categoria DP.

Esta ideia é corroborada pelos dados: na amostragem considerada neste estudo, ocorrem dados em que os nomes envolvidos na coordenação são usados para referir claramente entidades distintas, por exemplo, nomes relacionais que designam relações incompatíveis, no sentido em que nelas não pode estar envolvida simultaneamente uma mesma entidade, como acontece em (58), com os nomes "mulher e filho", e em (59), com os nomes "empregada e patroa", e também com nomes não relacionais mas que remetem necessariamente para entidades distintas, como em (60), com os nomes "dólar e iene".

(58) Está em São Filipe, com a mulher e filho nas tendas instaladas no aeroporto, mas espera voltar daqui a três meses e quando um «caterpillar» já tiver suavizado a passagem da lava.

(par=ext1200439-clt-soc-95a-1)

(59) O miúdo, dormindo, é posto no banco de trás, entre as duas mulheres, a empregada e patroa. (par=ext508426-clt-98a-1) 
(60) Em Inglaterra, a possibilidade de a libra alterar a sua banda de flutuação no SME será argumento suficiente para a sua próxima valorização contra o marco alemão, o qual se valorizou durante o período em análise principalmente contra o dólar e iene.

(par=ext1166524-nd-91b-1)

Estes são, na verdade, os dados que nos colocam o maior desafio, pois ilustram a possibilidade, para alguns falantes, de ocorrência de apenas um determinante com nomes que referem entidades tomadas de forma independente. Tal como os autores atrás mencionados, assumimos que o facto de o DP desencadear concordância no plural é uma evidência dessa independência referencial dos nomes envolvidos.

A análise destas construções passa por uma avaliação da estrutura sintática nelas presente. Esta estrutura deverá permitir explicar o contraste que se estabelece com as construções analisadas em 4.1, em que o DP desencadeia concordância no singular. Com efeito, neste caso, o facto de o DP desencadear concordância no plural mostra que este é o valor de número associado à categoria que resulta da coordenação, apesar de o determinante poder apresentar uma forma singular.

A hipótese de, neste caso, estarmos perante uma estrutura de coordenação de DPs (DP\&DP) parece, à partida, a que mais naturalmente permite captar os contrastes observados: assumindo que o valor referencial de uma expressão nominal resulta de uma operação de determinação que faz com que essa expressão designe um determinado referente, isto é, assumindo que é a combinação do nome comum com o determinante definido que permite que a expressão nominal designe uma entidade do universo do discurso, parece lógica a assunção de que, havendo um só determinante definido, existirá um só referente, enquanto a ocorrência de dois determinantes definidos conduzirá a que as expressões nominais designem referentes distintos, uma vez que cada um deles contribui para a construção de um valor referencial independente.

Se assumirmos esta hipótese, poderemos adotar, na linha do que foi proposto por alguns autores, como Camacho (2003), uma análise baseada na elipse sob identidade do segundo determinante. Com efeito, como referimos anteriormente, é desta forma que o autor referido explica, por um lado, a ocorrência de apenas um determinante com nomes abstratos e, por outro lado, a concordância do determinante com o primeiro termo coordenado.

Esta hipótese apresenta uma primeira vantagem de explicar naturalmente a forma como, em PE, se realiza a concordância com os elementos pré-nominais, neste caso, o determinante artigo definido. Como foi notado em Colaço (2012) e (2016), os determinantes concordam obrigatoriamente com o primeiro termo coordenado, como se pode ver nos dados que apresentamos em (61). Com efeito, o contraste entre (61a) e (61b) comprova que o determinante não concorda com valores resolvidos da categoria resultante da coordenação. ${ }^{8}$ Por outro lado, apesar de (61d) ser aceite apenas por alguns falantes, a clara agramaticalidade de (61c) aponta também neste mesmo sentido.

(61) a. Os livros e revistas que chegaram hoje já estão na estante.

b. *Os revistas e livros que chegaram hoje já estão na estante.

c. *As livros e revistas que chegaram hoje já estão na estante.

d. ?/Ok As revistas e livros que chegaram hoje já estão na estante.

Então, nestes casos, a concordância com o primeiro nome encontraria uma explicação no facto de o determinante realizado nestas construções ser, na realidade, o primeiro determinante, ou seja, aquele que foi inserido no interior do primeiro DP coordenado. Esta ideia poderá ser usada para explicar os dados que

\footnotetext{
${ }^{8}$ Os valores resolvidos seriam, neste caso, masculino plural, independentemente da posição relativa dos termos coordenados.
} 
recolhemos correspondentes aos três paradigmas observados. Como vimos atrás, os três paradigmas têm em comum o facto de o determinante partilhar os valores de género e número do primeiro nome:

\section{(62) Paradigma A: D_Fem-N_Fem-e-N_Masc \\ Paradigma B: D_Pl-N_Pl-e-N_Sg \\ Paradigma C: D_Sg-N_Sg-e-N_Sg}

Por outro lado, como já foi referido, não foram encontrados dados (ou foi encontrado um número mínimo de dados) para os paradigmas observados em que não se verifica essa partilha entre o determinante e o primeiro nome.

A segunda vantagem da assunção da hipótese DP\&DP reside no facto de permitir explicar a coexistência de estruturas com um só determinante (realizado) com a concordância com valores resolvidos: como vimos atrás, nos casos em que os nomes envolvidos nesta construção designam conceitos ou entidades distintos, a ocorrência de um só determinante não impede que o DP desencadeie concordância no plural, mesmo quando o determinante e os nomes têm um valor singular. Recordemos os seguintes exemplos:

(63) O actor e actriz é difícil de dizer, mas talvez fossem António Vilar (Igrejas Caeiro pela certa) e Leonor Maia.

(par=ext872004-clt-95a-1)

(64) A linguagem e estilo de Ribeiro são inconfundíveis, mas é interessante como ele explora, quando trabalha com os bailarinos do Ballet Gulbenkian, um virtuosismo mais expansivo e amplo.

(par=ext819212-soc-96b-1)

Assumindo que a expressão nominal "o actor e actriz", na frase (63), tem a estrutura sintática representada em (65), podemos sugerir que, sendo ambos os DPs construídos plenamente em sintaxe, os valores dos seus traços são combinados de acordo com o processo standard de resolução (i.e. através de regras de resolução, cf. Corbett 1984 a.o.), o que dá origem aos traços valorados que se associam ao DP que resulta da coordenação. Estando estes traços ativos, o DP poderá participar em operações sintáticas de concordância, como acontece nas frases de (63) e (64).

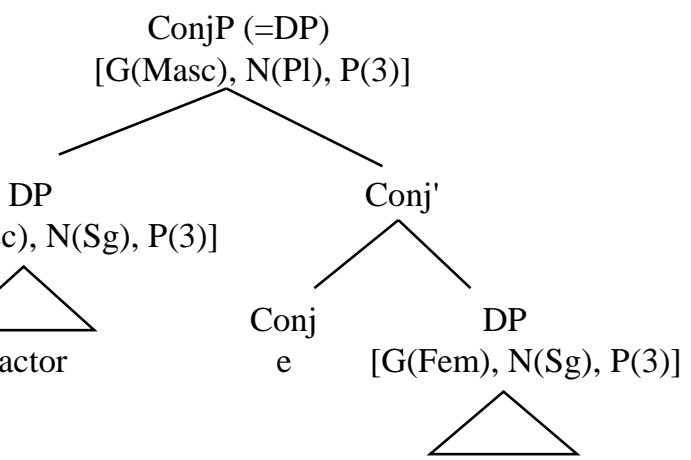

a actriz

Esta hipótese, que se baseia na análise sugerida por Camacho (1999) e (2003) para o espanhol, embora com diferentes pressupostos, como foi explicado na secção 4, implica, então, considerar que, sendo a estrutura sintática construída com dois determinantes, a omissão do segundo decorre de um apagamento pós-sintático, que dará origem a sequências como as ilustradas em (66): 
(66) a. [DP $\mathrm{O}$ actor] e [DP a actriz]

b. [DP a linguagem] e [DP $\theta$ estilo]

Camacho (2003) propõe que a omissão do determinante decorre de um apagamento sob identidade. A direcionalidade do apagamento, que apenas pode afetar o segundo determinante, como se vê em (67), é justificada pelo autor pela relação de c-comando assimétrico que se assume existir entre os termos coordenados: uma vez que o primeiro DP c-comanda assimetricamente o segundo DP, é esperável que o apagamento ocorra neste último.

(67) a. *Actor e a actriz talvez fossem António Vilar e Leonor Maia.

b. *Linguagem e o estilo de Ribeiro são inconfundíveis.

Embora a proposta do autor não seja explícita quanto a este aspeto, torna-se, no entanto, necessário postular que o requisito de identidade que permite o apagamento do segundo determinante não obriga a identidade morfológica dos determinantes ${ }^{9}$ : por, na análise que assumimos, não estarem associados ao mesmo referente, os determinantes envolvidos nestas construções podem ser distintos no que diz respeito aos valores de género e/ou número. É o que acontece em dados como os apresentados acima em relação ao traço de género e o que acontece, por exemplo, em (68) em relação ao traço de número:

(68) a. Os brancos são, quase sempre, servidos muito frios, o que lhes prejudica os aromas e sabor. (par=ext77303-soc-92b-2)

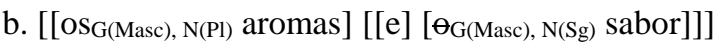

O facto de, nestas construções, o determinante apagado não estar associado ao mesmo referente do primeiro leva-nos a assumir, contrariamente a Camacho (2003), que os determinantes dos DPs coordenados não estão coindexados e que o apagamento do segundo determinante não está sujeito a um requisito de identidade estrita.

Note-se que, em qualquer destes casos em que cada DP coordenado refere uma entidade distinta, a ocorrência de apenas um determinante alterna com a possibilidade de realização de um determinante no interior de cada um dos DPs coordenados, sendo esta última a expressão nominal mais comummente aceite pelos falantes.

(69) a. o actor e actriz

b. o actor e a actriz

(70) a. a linguagem e estilo

b. a linguagem e o estilo

(71) a. os aromas e sabor

b. os aromas e o sabor

\footnotetext{
${ }^{9}$ Note-se que, em diversos casos de elipse, a relação que se estabelece entre o material elidido e o material com realização lexical que permite recuperar o conteúdo da elipse não é uma relação de identidade estrita, como se pode ver nos exemplos seguintes:

(i) O Pedro trabalhou com a Ana e os colegas com a Francisca. [trabalharam]

(ii) O Pedro é professor e a Ana também. [professora]

(iii) Os meus pais são professores e eu também (sou). [sou professora]

Veja-se, a este respeito, Nunes e Zocca (2009), sobre falta de identidade morfológica entre a elipse e o seu antecedente em português brasileiro.
} 


\subsection{Casos de ambiguidade}

Quando não desencadeiam concordância com outros elementos, as expressões nominais com uma estrutura coordenada e apenas um determinante tornam-se ambíguas quando os nomes envolvidos permitem a possibilidade de interpretação de referência conjunta e de referência independente. De acordo com a proposta que apresentámos nas secções anteriores, estas serão situações de ambiguidade sintática ou estrutural. Assim, frases como as ilustradas em (72) e (73), por exemplo, podem ser analisadas enquanto contendo uma expressão nominal com uma estrutura de coordenação de NPs ou com uma estrutura de coordenação de DPs.

(72) Estes dados são o resultado de uma sondagem Eurobarómetro sobre o conhecimento e aceitação do Tratado de Maastricht em Portugal por partidos políticos.

(par=ext1324910-pol-92a-1)

(73) As empresas cotadas nas duas Bolsas serão obrigadas este ano a contratar um auditor externo para analisar as contas e balanço de 1992.

(par=ext74742-eco-93a-1)

Com efeito, dada a natureza dos nomes envolvidos, que permitem uma interpretação conjunta, as expressões "o conhecimento e aceitação (...)" e "as contas e balanço (...)" podem corresponder a DPs com uma estrutura de coordenação de NPs com inserção de apenas um determinante, denotando a interseção das denotações dos respetivos nomes. No entanto, alternativamente, podem também corresponder a uma estrutura de coordenação de DPs com omissão do segundo determinante, uma vez que a sua interpretação pode ser equivalente à das expressões com dois determinantes "o conhecimento e a aceitação (...)" e "as contas e o balanço (...)". A opção por uma estrutura ou pela outra depende, então, da intenção de considerar as entidades designadas pelos nomes de uma forma conjunta ou de uma forma independente.

Contrariamente ao que acontece em (72) e (73), em (74) e (75) - que retomam, respetivamente, (58) e (26) -, as expressões nominais que ocorrem não geram ambiguidade, uma vez que os nomes envolvidos na coordenação - "mulher e filho" e "vodka e saké" - são necessariamente independentes do ponto de vista referencial, isto é, referem obrigatoriamente entidades distintas:

(74) Está em São Filipe, com a mulher e filho nas tendas instaladas no aeroporto, mas espera voltar daqui a três meses e quando um «caterpillar» já tiver suavizado a passagem da lava.

(par=ext1200439-clt-soc-95a-1)

(75) Os cientistas experimentaram fabricar estes filmes utilizando quase todas as matérias primas imagináveis - segundo alguns relatos, entre os materiais experimentados conta-se, por exemplo, o vodka e saké.

(par=ext1120927-nd-91a-1)

Com efeito, como notámos atrás, a característica central que permite distinguir estas duas estruturas reside no facto de a inserção de apenas um determinante no início da derivação apenas ser possível quando existe um referente que possa ser designado pela interseção das propriedades designadas pelos nomes envolvidos na coordenação. 


\section{Conclusões}

O objetivo deste trabalho foi, partindo do estudo apresentado em Colaço \& Gramacho (2018), analisar a forma como se realiza a concordância em construções que envolvem expressões nominais com uma estrutura coordenada com apenas um determinante.

Os dados de corpora considerados tinham já mostrado, no trabalho referido acima, que, em PE, para além das expressões nominais coordenadas com apenas um determinante em que os nomes envolvidos na coordenação são usados para referir conjuntamente a mesma entidade, que são comummente consideradas aceitáveis quer pelos próprios falantes quer nas descrições gramaticais, alguns falantes produzem expressões nominais coordenadas com apenas um determinante em que os nomes são usados para referir entidades distintas, mostrando a possibilidade de a presença de apenas um determinante ser compatível com a ocorrência da conjunção copulativa com um valor de reunião e não de interseção. Para distinguirmos estes dois tipos de construções, centrámo-nos especialmente nas estruturas que envolvem um determinante no singular e dois nomes também no singular, uma vez que este é o contexto em que a realização morfológica do determinante definido traz maiores evidências. Como ponto de partida para essa distinção, observámos o tipo de concordância desencadeada pela expressão nominal: concordância no singular versus concordância no plural.

A proposta que apresentámos centra-se na ideia de que estas construções correspondem a estruturas que são distintas desde o início da derivação sintática, diferindo no que diz respeito às categorias envolvidas na coordenação e em relação ao número de determinantes selecionados para a numeração. Assim:

Nas construções em que os nomes são usados para referir uma mesma entidade, é inserido apenas um determinante na numeração e a coordenação é realizada ao nível do NP. Neste caso, o determinante definido concorda com o primeiro termo coordenado através de uma relação de c-comando assimétrico local. Quando o determinante ocorre numa forma do singular, o DP desencadeia concordância no singular.

Por outro lado, nas construções em que os nomes são usados para referir entidades distintas, a coordenação é realizada ao nível do DP, na linha do que foi sugerido por Camacho (2003) para o espanhol, sendo inserido, na numeração, um determinante no interior de cada DP, verificando-se o apagamento póssintático do segundo determinante por identidade (não estrita). Sendo apagado na componente fonética, o segundo determinante não é soletrado, mas o valor referencial do segundo DP coordenado é construído e interpretado na componente semântica, o que explica o facto de, neste caso, o DP cimeiro, resultante da coordenação, desencadear concordância no plural.

A análise que propomos para o PE concilia, assim, aspetos de diferentes propostas sugeridas por outros autores para outras línguas, apresentando as vantagens de, por um lado, explicar de uma forma simples o modo como se realiza a concordância no interior das expressões nominais consideradas neste trabalho, e de, por outro lado, explicar de forma igualmente simples o facto de expressões nominais coordenadas com apenas um determinante realizado em que tanto o determinante como os nomes ocorrem no singular poderem desencadear concordância no plural.

\section{Referências}

Camacho, J. (1999) La coordinación. In Bosque, I. \& V. Demonte (eds.) Gramática Descriptiva de la Lengua Española. Madrid: Espasa-Calpe, pp. 2635-2695.

Camacho, J. (2003) The Structure of Coordination: Conjunction and Agreement Phenomena in Spanish and other Languages. Dordrecht, Kluwer Academic Press. 
Chomsky, N. (2000) Minimalist inquiries: The framework. In R. Martin, D. Michaels \& J. Uriagereka (eds.). Step by Step: Essays in Minimalist Syntax in Honor of Howard Lasnik. Cambridge, Mass: MIT Press, pp. 89-155.

Chomsky, N. (2001) Derivation by Phase. In Kenstowicz, M. (ed.) Ken Hale: a Life in Language. Cambridge, Mass.: MIT Press, pp. 1-52.

Colaço, M. (2012) Retomando a questão da concordância parcial no interior de constituintes nominais coordenados. A. Costa, I. Falé \& P. Barbosa (eds.) Textos Seleccionados do XXVII Encontro Nacional da Associação Portuguesa de Linguística 2011. Lisboa: Edições Colibri/APL, pp. 153-170.

Colaço, M. (2016) Especificidades das estruturas de coordenação: padrões de concordância. In Martins, A. M. \& E. Carrilho (eds.) Manual de Linguística Portuguesa. Germany: The Gruyter, pp. 502-522.

Colaço, M. \& C. Gramacho (2018) (aceite para publicação). Coordenação de constituintes nominais com apenas um determinante em português europeu. In Carrilho, E., A. M. Martins, S. Pereira \& J. P. Silvestre (orgs.) Estudos Linguísticos e Filológicos Oferecidos a Ivo Castro. Centro de Linguística da Universidade de Lisboa, ebook [open access].

Costa, J. \& S. Pereira (2005) Phases and autonomous features: a case of mixed agreement in European Portuguese. In McGinnis, M. \& N. Richards (eds.) Perspectives on Phases. Cambridge, Mass.: MIT Press, pp. 115-124.

Cunha \& Cintra (1984) Nova Gramática do Português Contemporâneo. Lisboa: Sá da Costa.

D'Alessandro, R. (2004a) Syntactic and Pragmatic Features: A case study. Leitura: Estudos em syntaxe comparativa, 33, pp. 185-202.

D'Alessandro, R. (2004b) Impersonal si Constructions. Agreement and Interpretation. Ph.D. Dissertation, University of Stuttgart. (Published as Impersonal si Constructions. Berlin: Mouton de Gruyter, 2007)

Demonte, V., H. F. Alcalde \& I. P. Jiménez (2009) Singular DPs with plural denotation and the features of D. Abstract presented at Journées d'étude sur la pluralité nominale et verbale - International workshop on nominal and verbal plurality. Paris.

Demonte, V., H. F. Alcalde \& I. P. Jiménez (2011) On the nature of nominal features - Agreement mismatches in Spanish conjoined structures. In Herschensohn, J. (ed.) Romance Linguistics 2010: Selected papers from the 40th SRL. Seattle, Washington, pp. 177-190.

Demonte, V. \& Jiménez, I. P. (2012) Closest Conjunct Agreement in Spanish DPs. Syntax and beyond. Folia Linguistica 2012, 46 (1).

Frampton, J. \& S. Gutmann (2000) Agreement is Feature Sharing. Unpublished Manuscript, Northeastern University.

Frampton, J. \& S. Gutmann (2006) How Sentences Grow in the Mind. In Boeckx, C. (ed.) Agreement Systems. Amsterdam: J. Benjamins, pp. 121-157.

Heycock, C. \& R. Zamparelli (2005) Friends and colleagues. Plurality, coordination and the structure of DP. NLS 13, pp. 201-270.

King, T. H. \& M. Dalrymple (2004) Determiner agreement and noun conjunction. Journal of Linguistics 40(1), pp. 69-104.

Matos \& Raposo (2013) Estruturas de Coordenação. In Raposo, E. P. et al. (orgs.) Gramática do Português. Lisboa: FCG, pp. 1759-1817.

Nunes, J. \& C. Zocca (2009) Lack of morphological identity and ellipsis resolution in Brazilian Portuguese. In Nunes, J. (ed.) Minimalist Essays on Brazilian Portuguese Syntax. Amsterdam: Jonh Benjamins, pp. 215-236.

Peres, J. (2013) Semântica do Sintagma Nominal. In Raposo, E. P. et al. (orgs.) Gramática do Português. Lisboa: FCG, pp. 735-818.

Raposo, E. P. \& M. Miguel (2013) Introdução ao Sintagma Nominal. In Raposo, E. P. et al. (orgs.) Gramática do Português. Lisboa: FCG, pp. 703-734.

Villavicencio, A., L. Sadler \& D. Arnold (2005) An HPSG account of Closest Conjunct Agreement in NP coordination in Portuguese. In Müller, S. (ed.) Proceedings of the HPSG Conference. Stanford: CSLL. 